\title{
173
}

Reni Budi Setianingrum

Fakultas H ukum U niversitas

M uhammadiyah Yogyakarta

reni.setianingrum@law.umy.ac.id

\section{Pengelolaan Sampah Dengan Pola 3 R Untuk Memperoleh Manfaat} Ekonomi Bagi Masyarakat

https:/ / doi.org/ 10.18196/ bdr.6244

\begin{abstract}
The purpose of this community service program are to change the previous paradigm of local people who assumed that waste is a useless material, to a new paradigm which believed that waste can be potential a raw material for handicraft that have economic value, provide skill through training to make handicraft made from plastic waste and change the old pattern of collect-transport-throw away, into $3 R$ patterns, ie reduce, reuse and recycle and also establish a waste management group. The method of this community service program was implemented in 3 (three) stages, Firstly counseling in improving environmental awareness. Secondly, training how to recycle plastic crackle and sachet, and thirdly, assisting garbage management group. The result of this service program are that there is a change of paradigm of the service program's partners who previously throw garbage carelessly, recently they are already have awareness of sorting the waste between non recyclable and recyclable, citizens also have the skills to produce handicrafts made from the raw materials of plastic waste. In addition, there is existing group which is expected to be the future "Bank Sampah".

Keywords $=$ waste, recycle, plastic waste.
\end{abstract}

\section{PENDAHULUAN}

Program pengabdian Kuliah Kerja Nyata D esa M itra (KKN PPM) merupakan salah satu program pengabdian yang diselenggarakan oleh Lembaga Penelitian, Publikasi dan Pengabdian M asyarakat (LP3M) U niversitas M uhammadiyah Yogyakarta. Pengabdian ini dilaksanakan dengan tujuan untuk meningkatkan kapasitas dan pengalaman mahasi swa dalam berfikir, berinteraksi, berkomunikasi dan bekerjasama dalam kegiatan pengabdian dan pemberdayaan dengan masyarakat dan pemerintahan di desa yang telah menjadi mitra U MY sebagai perwujudan dari salah satu Tri D harma perguruan tinggi. Lokasi pengabdian dalam program pengabdian KKN PPM ini adalah di Dusun Jayan, yang merupakan wilayah dari D esa Kebonagung Kecamatan Imogiri, Bantul.

Permasalahan yang cukup krusial yang ada di dusun Jayan adalah permasalahan 
sampah, mulai dari rendahnya kesadaran dan pengetahuan masyarakat mengenai pemilahan, pen golahan dan daur ulang sampah. Tidak tersedianya tempat pembuangan sampah/ rumah pilah sampah, sehingga sampah menumpuk dan tidak bermanfaat, tidak sedap dipandang dan mencemari lingkungan tinggal, serta belum adanya Bank Sampah.

Sampah memang merupakan permasalahan multidimensi dan terjadi hampir di seluruh wilayah Indonesia. M enurut data Jurnal science pada tahun 2015 lalu, Indonesia merupakan pembuang sampah plastik ke lautan terbanyak nomor 2 di dunia setelah China. ${ }^{1}$ D isebutkan, setiap tahun lautan di seluruh dunia dipenuhi sampah plastik hingga 12,7 juta ton. Indonesia sendiri menempati urutan nomor dua disusul Filipina, Vietnam dan Sri Lanka. ${ }^{2}$

M asyarakat umumnya hanya tahu bahwa pemerintahlah yan g bertanggung jawab pada pengelolaan sampah, khususnya karena masih terpaku pada pola kumpul, angkut dan buang dari TPS (Tempat Pembuangan sampah Sementara) keTPA (Tempat Pembuangan sampah A khir). ${ }^{3}$ Pengelolaan sampah bukan hanya tanggung jawab pemerintah, akan tetapi merupakan tanggung jawab bersama antara pemerintah dan penghasil sampah, baik penghasil sampah yang berupa orang pribadi/ keluarga maupun korporasi.

D efinisi mengenai sampah perlu kita pahami terlebih dahulu sebelum kita membahas mengenai pengolahan sampah secara lebih mendalam. M enurut Pasal 1 angka 1 U ndang Undang Nomor 18 Tahun 2008 tentang Pengelolaan Sampah, sampah adalah sisa kegiatan sehari-hari manusia dan/ atau proses alam yang berbentuk padat. ${ }^{4}$

Berdasarkan tingkat penguraian, sampah pada umumnya dibagi menjadi dua macam yaitu sampah organik dan an organik. Sampah organik berupa sampah yang mengandung senyawa-senyawa organik, karena tersusun dari unsur-unsur seperti $\mathrm{C}, \mathrm{H}, \mathrm{O}, \mathrm{N}$ dan sebagainya. Sampah organik umumnya dapat terurai secara alami oleh mikroorganisme, contohnya sisa makanan, karton, kain, karet, kulit, sampah halaman. Sampah anorganik adalah sampah yang bahan kandungannya bersifat anorganik dan umumnya sulit terurai oleh mikroorganisme. Contohnya: kaca, kaleng, alumunium, debu, dan logam lainnya.

Menurut Bambang Wintoko dalam bukunya yang berjudul "Panduan Praktis M endirikan Bank Sampah", berdasarkan sumbernya, sampah dapat digolongkan menjadi 2 (dua) kelompok besar, yaitu sampah domestik dan sampah non domestik. ${ }^{5}$ Sampah domestik, yaitu sampah yang sehari-harinya dihasilkan akibat kegiatan manusia secara langsung, misalnya sampah rumah tangga, sampah pasar, sampah dari pusat keramaian dan sampah Rumah Sakit. Sampah domestik ini sendiri dapat dibagi menjadi:

a) Sampah dari pemukiman, umumnya sampah rumah tangga berupa sisa pengolahan 
makanan, barang bekas, sampah kebun dan halaman.

b) Sampah dari perdagangan, yaitu sampah yang berasal dari daerah perdagangan, seperti toko, pasar tradisional, pasar swalayan, biasanya berupa kardus, sampah makanan restoran, dan bekas kemasan makanan

c) Sampah yang berasal dari lembaga pendidikan, kantor pemerintah dan swasta, biasanya berupa sisa alat tulis.

Sampah Non Domestik, yaitu sampah yang sehari-hari dihasilkan oleh kegiatan manusia secara tidak langsung, seperti dari pabrik industri, pertanian, peternakan, perikanan, kehutanan dan sebagainya. Sampah non domestik ini dapat dibagi menjadi:

a) Sampah industri, berasal dari rangkaian proses produksi, biasanya berupa bahan kimia yang memerlukan perlakuan khusus sebelum dibuang

b) Sampah dari sisa bangunan dan konstruksi gedung, bisa berupa bahan organik seperti kayu dan an organik seperti semen dan besi. ${ }^{6}$

Jenisjenis sampah dapat dilihat di Pasal 2 Undang U ndang N omor 18 Tahun 2008 tentang Pengelolaan Sampah, yaitu sampah rumah tangga, berupa sampah yang berasal dari kegiatan sehari-hari dalam rumah tangga, tidak termasuk tinja dan sampah spesifik, sampah sejenis sampah rumah tangga, berupa sampah yang berasal dari kawasan komersial, kawasan industri, kawasan khusus, fasilitas sosial, fasilitas umum, dan/atau fasilitas lainnya, dan sampah spesifik, yaitu sampah yang karena sifat, konsentrasi, dan/atau volumenya memerlukan pengelolaan khusus. Sampah spesifik ini terdiri atas sampah yang mengandung bahan berbahaya dan beracun, sampah yang mengandung limbah bahan berbahaya dan beracun, sampah yang timbul akibat bencana, puing bongkaran bangunan dan sampah yang secara teknologi belum dapat diolah; dan/atau sampah yang timbul secara tidak periodik.

UndangU ndang N omor 18 tahun 2008 tentang Pengelolaan Sampah mengamanatkan bahwa paradigma pengelolaan sampah harus dirubah dari kumpul-angkut-buang menjadi pengurangan di sumber dan daur ulang sumberdaya. Pendekatan end of pipediganti dengan prinsip 3R (reduce, reuse, recycle).

Prinsip $3 R$, yaitu Reduce, Reuse, dan Recycle, merupakan paradigma baru penanganan sampah dari yang sebelumnya "kumpul-angkut-buang" menjadi "kumpul-pilah-olahangkut". ${ }^{7}$ Konsep $3 \mathrm{R}$ (Reduce, Reuse, Recycle) dapat didefinisikan sebagai ${ }^{8}$ Reduce (pengurangan), Reuse (pemakaian kembali) dan Recycle (daur ulang). 
Pelaksanaan konsep $3 \mathrm{R}$ ini dapat dijabarkan lebih lanjut sebagai berikut: ${ }^{9}$

a) Reduce (mengurangi) dengan cara mengurangi penggunaan barang yang berpotensi menghasilkan banyak sampah, menghindari barang sekali pakai, menggunakan produk yang bisa diisi ulang (refill), dan dengan mengurangi penggunaan kantong plastik saat berbelanja.

b) Reuse (penggunaan kembali), yaitu dengan menggunakan barangyang dianggap sampah untuk fungsi yang berbeda, misalkan menggunakan kertas bekas untuk menjadi pembungkus. Reuse dapat memperpanjang umur dan waktu pemakaian barang sebelum dibuang ke tempat sampah.

c) Recycle (mendaur ulang), dilakukan dengan mengubah barang bekas menjadi benda lain yang lebih berguna dan layak pakai. M isalnya mengubah botol bekas menjadi vas bunga.

Sampah bukanlah sesuatu yang harus dijauhi, justru sampah harus dikelola dengan benar. Pengelolaan sampah harus dilihat sebagai cost recovery dengan memanfaatkan sampah sebagai bahan baku pembuatan produk yang memiliki nilai jual secara ekonomis. ${ }^{10}$ Secara singkatnya benda yang memiliki nilai ekonomi adalah barang yang memiliki nilai jual.

Sampah dapat digunakan menjadi bahan baku bagi proses daur ulang untuk menjadi barang lain yang bermanfaat. U ntuk membuat sampah dapat memiliki nilai ekonomi, maka proses yang dilakukan adalah recycle atau daur ulang sampah menjadi benda lain yang lebih berguna dan layak pakai. ${ }^{11 S a m p a h ~ o r g a n i k ~ d a p a t ~ d i o l a h ~ m e n j a d i ~ k o m p o s, ~}$ biogas, sampah plastik dapat diolah menjadi produk kerajinan tangan. ${ }^{12}$

Berdasarkan uraian diatas, maka program pengabdian ini memilih tema pengelolaan sampah dengan pola $3 \mathrm{R}$ untuk memperoleh manfaat ekonomi bagi masyarakat. Pengabdian ini dilaksanakan bekerjasama dengan mahasiswa kelompok 027 D usun Jayan, warga D usun Jayan sebagai mitra pen gabdian dan penyuluh dari Jejaring Pen gelola Sampah M andiri (JPSM ) D aerah Istimewa Yogyakarta yang diwakili oleh I bu Sulastriningsih dan pihak D inas Lingkungan H idup Kabupaten Bantul.

Program pengabdian ini dimaksudkan untuk mengubah paradigma masyarakat setempat yang semula meman dang sampah sebagai barang tidak berguna, menjadi bahan baku kerajinan yang punya nilai ekonomis. M asyarakat juga diharapkan dapat mengubah pola lama kumpul-angkut-buang, menjadi pola $3 R$, yaitu reduce, reuse dan recycle (mengurangi, menggunakan kembali, dan mendaur ulang). Selain itu, untuk mendampingi masyarakat dalam merintis sebuah Bank Sampah mandiri. 


\section{METODE PELAKSANAAN}

Pemberdayaan masyarakat adalah suatu proses dimana masyarakat mampu meningkatkan pemahamannya secara mandiri. Aspek penting dalam suatu program perberdayaan masyarakat salah satunya adalah program dan strategi yang disusun sendiri oleh masyarakat. Sebelum program dilaksanakan, akan dilakukan assesment dan sosialisasi. A dapun dalam menyelesaikan permasalahan yang ada di wilayah mitra, program pen gabdian ini dilaksanakan dengan beberapa metode, yaitu penyuluhan, pelatihan bimbingan teknis dan pendampingan. Untuk mengukur tingkat keberhasilan program, maka pada akhir program akan dilaksanakan evaluasi bersama.

Penyuluhan dilaksanakan bertujuan untuk meningkatkan kesadaran lingkungan warga dan dilakukan dengan pemberian data dan informasi mengenai bahaya sampah. Penyuluhan ini dilaksanakan untuk mengatasi permasalahan rendahnya kesadaran masyarakat untuk bertanggung jawab dan memilah sampah yang dihasilkan.

Pelatihan berupa bimbingan teknis daur ulang sampah plastik menjadi kerajinan tangan yang memiliki nilai ekonomi, yaitu tas dan bunga. Pelatihan ini akan diberikan bagi masyarakat etrutama ibu ibu agar memiliki keterampilan untuk mengolah sampah menjadi barang yang bermanfaat,. Program-program pelatihan ini dilaksanakan dengan metode yang sederhana, yaitu dengan menyelenggarakan pertemuan sekaligus dengan diskusi dan praktek sehingga masyarakat tidak terlalu berat dalam menerima materi-materi pelatihan.

M etode pendampingan akan dilaksanakan khusus bagi kelompok pengelola sampah untuk kemudian kelompok tersebut dibina menjadi rintisan Bank Sampah. Pendampingan ini dilaksanakan bekerjasama dengan Dinas Lingkungan Hidup. D alam proses pendampingan ini, tim memberikan solusi-solusi atas hambatan yang dihadapi oleh masyarakat melalui dialog yang intens. Pendampingan ini dilakukan agar program dapat terlaksana dengan baik atau merupakan penerapan hasil pelatihan yang dilakukan

\section{CAPAIAN PEMBERDAYAAN MASYARAKAT}

\section{A. PraProgram}

Kegiatan pertama yang dilaksanakan dalam program pengabdian ini adalah assesment yang dilaksanakan untuk mengenali permasalahan yan g terjadi di masyarakat. A ssesment ini dilaksanakan dengan mengadakan dialog dengan pimpinan, tokoh masyarakat dan perwakilan masyarakat. D ari dialog ini di temukan adanya beberapa permasalahan yang cukup krusial yang dialami masyarakat mitra, yaitu sebagai berikut: 
1) Rendahnya kesadaran masyarakat untuk bertanggung jawab dan memilah sampah yang dihasilkan;

2) Masyarakat tidak memiliki keterampilan untuk mengolah sampah menjadi barang yang bermanfaat;

3) Belum adanya Bank Sampah di wilayah Dusun Jayan, D esa Kebonagung, Kecamatan Imogiri, Bantul.

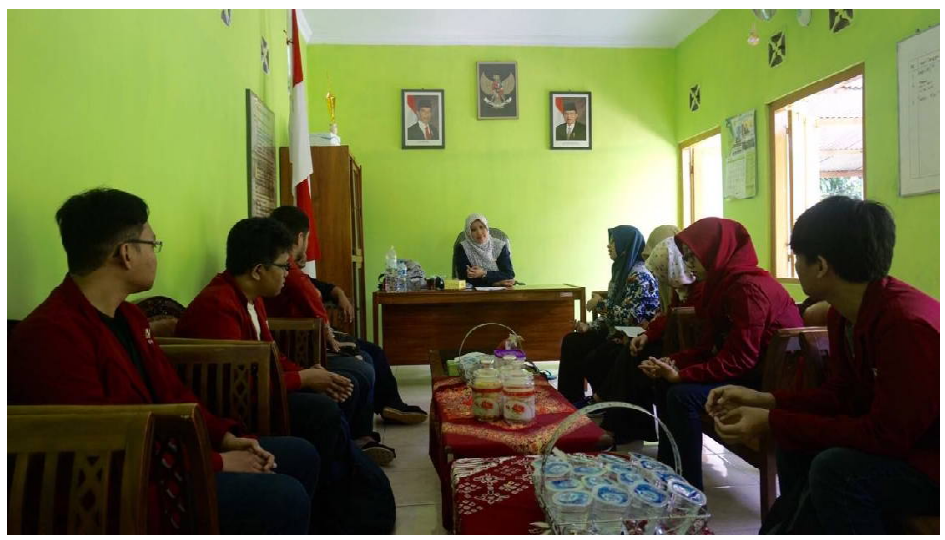

Gambar 1. Assesment bersama pemerintahan desa

Tahapan berikutnya adalah sosialisasi program kepada masyarakat mitra pengabdian . Dalam tahapan ini, masyarakat diajak untuk duduk bersama dalam sebuah pertemuan informal, secara bersama-sama membuat rencana dan strategi pengolahan sampah, berikut menyusun jadwal pelaksanaan program dan mengumpulkan sampah untuk bahan baku pelatihan.

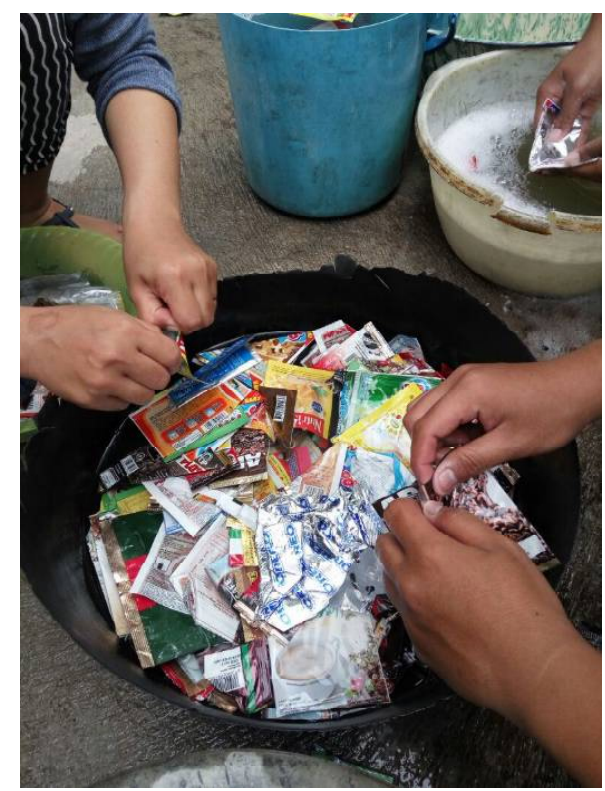

Gambar 2. Masyarakat berlatih memilah sampah plastik 


\section{9}

\section{B. Pelaksanaan Program}

Pelaksanaan program pengabdian dilaksanakan dengan tahapan-tahapan sebagai berikut:

1. Tahap penyuluhan, tahapan ini dilaksanakan setelah sosialisasi, dalam tahap ini, masyarakat diberikan informasi mengenai dampak negatif dari sampah yang tidak dikelola dengan baik, mulai dari dampak kesehatan, dampak sosial, dan dampak jangka panjang bagi lingkungan. Dalam tahap ini, masyarakat juga diajarkan untuk memilah sampah organik dan sampah anorganik, sampah anorganik dipilah kembali menjadi sampah anorganik yang dapat didaur ulang, dan sampah an organik yang tidak dapat didaur ulang. $\mathrm{H}$ al ini dimaksudkan agar volume sampah rumah tangga yang dibuang ke tempat pembuangan sampah lambat laun menjadi semakin berkurang volumenya.

2. Tahap pelatihan, dalam tahap ini masyarakat diberikan paradigma dan wawasan baru bahwa sampah plastik yang dihasilkan oleh rumah tangga dapat menjadi bahan baku kerajinan yang memiliki nilai ekonomis dan bimbingan teknis dalam daur ulang sampah. D alam pelatihan yang dilaksanakan bekerjasama dengan Jejaring Pengelola Sampah M andiri (JPSM ) Yogyakarta ini, masyarakat diberikan 2 (dua) tahap pelatihan.

a. Pelatihan tahap pertama kepada masyarakat untuk mengolah plastik kresek bekas menjadi bunga plastik, warga diberikan pelatihan bagaimana mengolah plastik kresek disetrika menjadi lembaran, lembaran plastik tersebut yang kemudian digunting sesuai pola dan warna menjadi bunga dan daun yang kemudian dapat dirangkai menjadi satu rangkaian bunga dalam pot. Pelatihan tahap kedua kepada masyarakat untuk mengolah plastik kemasan sachet kopi, shampoo dan snack yang kemudian digunting menjadi serpihan. Serpihan tersebut kemudian dijahit pada kain kasa dan menjadi lembaran bahan baku tas dan dompet.
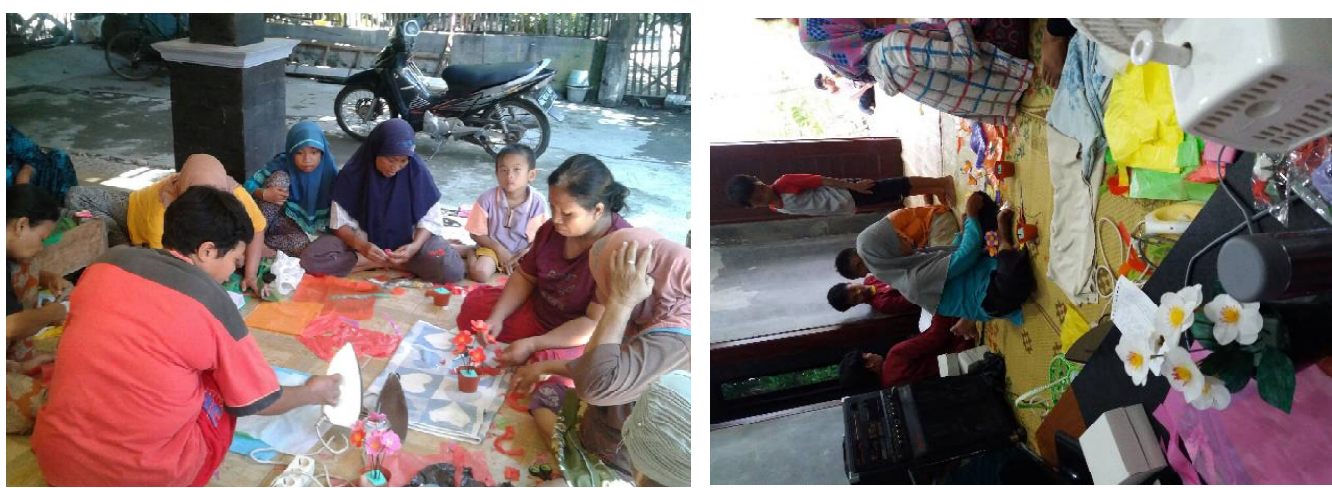

Gambar 2 dan 3. Pelatihan pembuatan bunga dari plastik kresek 


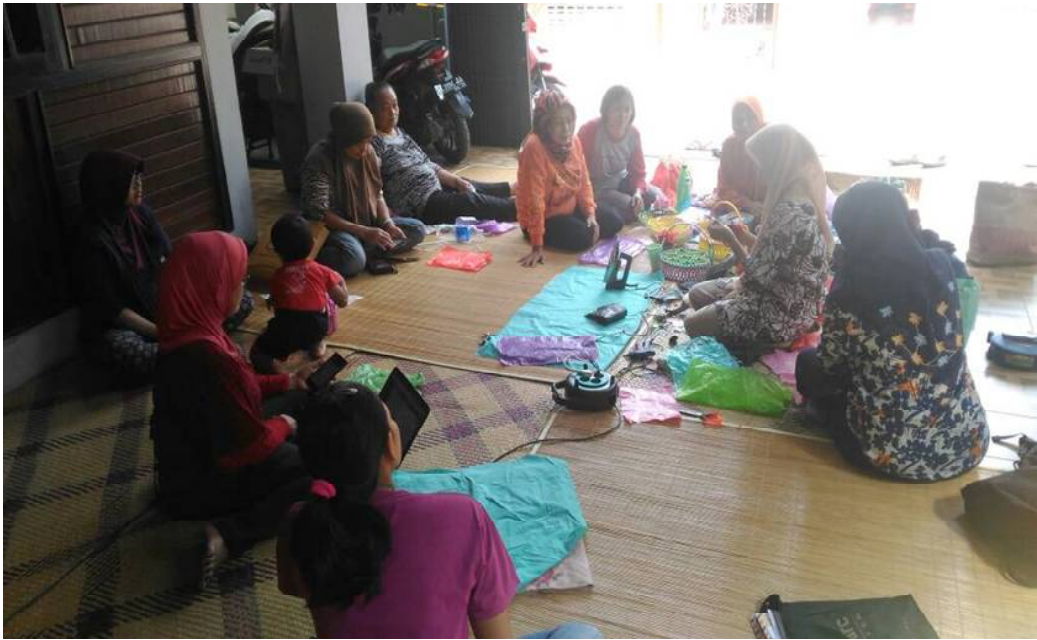

Gambar . Pelatihan pembuatan kerajinan dari sampah plastik

b. Pelatihan tahap ketiga berupa pelatihan dan bimbingan teknis dari Dinas Lingkungan Hidup kepada beberapa warga yang ditunjuk oleh pemerintah D esa untuk menjadi anggota kelompok pengelola sampah, terdiri dari pelatihan dasar dalam membuat program kerja, prosedur pendirian Bank Sampah, pedoman operasional bank sampah, termasuk diantaranya pelatihan administrasi dan pencatatan keuangan Bank Sampah.

3. Tahap pendampingan, tahapan ini dilaksanakan bersama-sama dengan tim dari D inas Lingkungan $\mathrm{H}$ idup setempat, pendampingan dilaksanakan dengan monitoring dan komunikasi intens dengan kelompok pengelola sampah, untuk mengetahui hambatan dan progress program kerja kelompok pengelola sampah.

\section{Keberhasilan Program}

Sebelum pelaksanaan program pen gabdian ini, belum ada masyarakat paham men genai pentingnya memilah sampah, semua jenis sampah dibuang den gan cara dicampur dan dibuang pada tanah kas warga. $\mathrm{H}$ al ini membuat bau tidak sedap di lokasi tanah kas desa dan timbunan sampah semakin bertambah dari waktu kewaktu. Setelah penyuluhan, hasil dari pemantauan tim selama 1 (satu) bulan, beberapa warga sudah mulai menimbun sampah organik dan hanya membuang sampah anorganik.

$\mathrm{H}$ asil dari program pengabdian pengelolaan sampah dengan pola $3 \mathrm{R}$ untuk memperoleh manfaat ekonomi bagi masyarakat ini adalah sebagai berikut, pasca penyuluhan, $>50 \%$ warga masyarakat mitra sudah mulai berinisiatif untuk memilah sampah rumah tangga yang dihasilkan, untuk sampah organik dilakukan penimbunan, sampah anorganik dipilah kembali menjadi anorganik yang dapat didaur ulang dan tidak dapat didaur ulang, hal tersebut mengurangi timbunan sampah warga dimana yang 


\section{1}

dibuang ke tempat pembuangan sampah hanyalah sampah yang betul-betul sudah tidak dapat dimanfaatkan kembali.

H asil dari pelatihan daur ulang, dari 40 (empatpuluh) peserta, 21 (duapuluh satu) diantaranya telah berhasil membuat bunga plastik dalam pot, dan 10 (sepuluh) orang berhasil membuat dompet dari serpihan kemasan sachet dan perca. Peserta lain yang belum dapat menyelesaikan praktek daur ulangnya maka melanjutkan dirumah dengan didampingi oleh tim. $\mathrm{H}$ asil ini ditindaklanjuti oleh kelompok arisan dengan membentuk komunitas ibu-ibu beranggotakan 10 (sepuluh) orang yang secarakonsisten telah mampu memproduksi kerajinan tangan berupa bunga berbahan plastik kresek dan tas berbahan baku guntingan kemasan sachet dan perca. Komunitas ini saat ini telah merintis promosi dan penjualan hasil produksi melalui sosial media whatsapp dan facebook.

Kegiatan pendampingan yang dilaksanakan bersama D inas Lingkungan H idup Bantul menghasilkan peningkatan kemampuan kelompok pengelola sampah dalam hal pengelolaan sampah, operasional Bank Sampah dan pengenalan kegiatan administrasi Bank Sampah. Setelah pelatihan dan bimbingan teknis dari D inas Lingkungan H idup, kelompok pengelola sampah telah mengajukan permohonan untuk memperoleh bantuan rumah pilah sampah kepada pemerintah Kabupaten Bantul, sekaligus mengajukan permohonan untuk menjadi Bank Sampah pada Dinas Lingkungan H idup K abupaten Bantul.
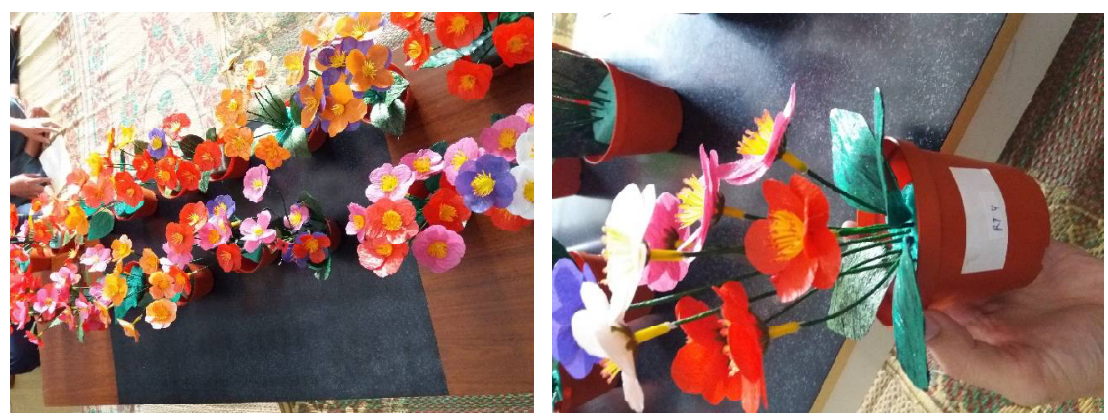

Gambar 4 dan 5. Hasil pengolahan plastik kresek menjadi bunga plastik
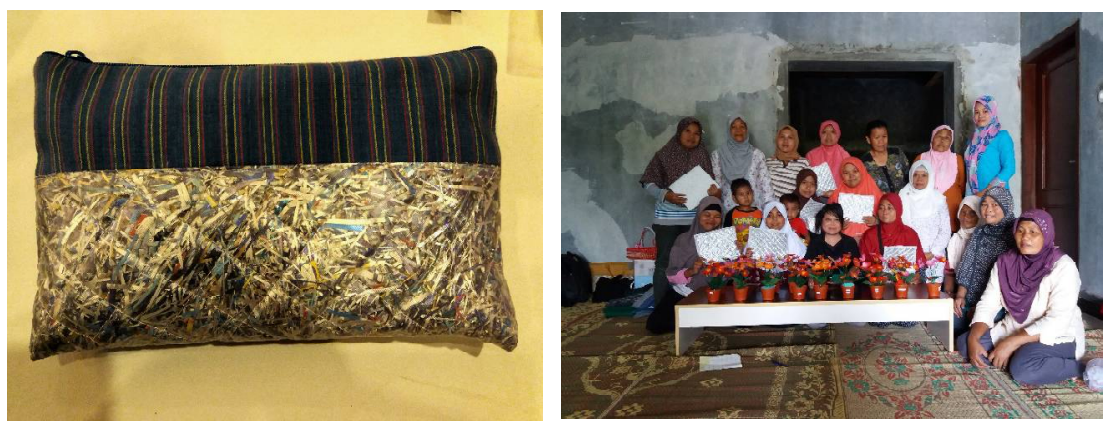

Gambar 6. Warga dan hasil karyanya

Gambar 7. Dompet hasil kerajinan warga 
Pada akhir program pengabdian, dilaksanakan evaluasi program pengabdian. Evaluasi program ini berupa dialog un tuk memproleh feedback dengan melibatkan warga, kelompok pengelola sampah dan wakil dari pemerintahan desa, evaluasi dilaksanakan untuk mengetahui manfaat program pengabdian, kekurangan dan hambatan pelaksanaan pengabdian, serta masukan dari mitra pengabdian mengenai keberlanjutan program.

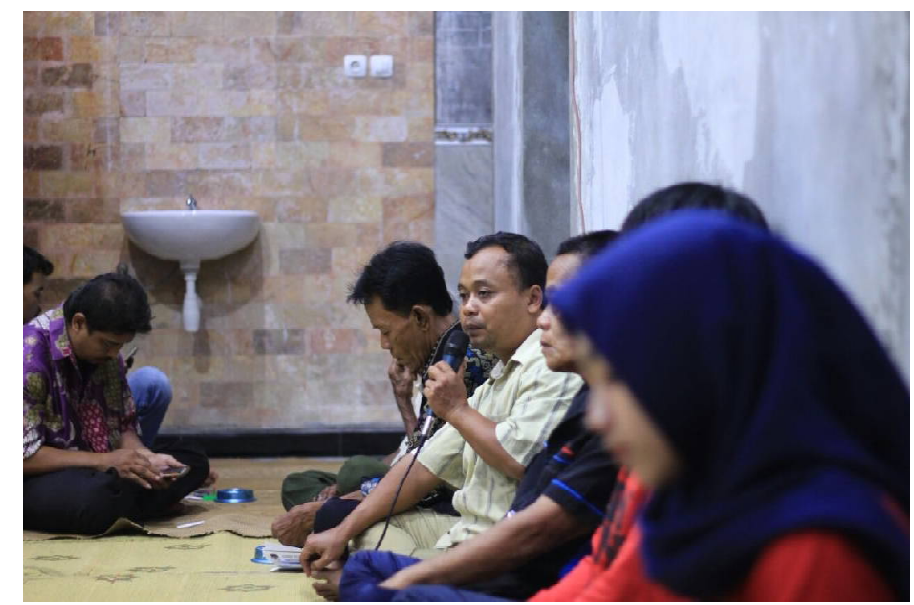

Gambar 8. Evaluasi bersama dengan tokoh masyarakat

H asil evaluasi bersama dengan masyarakat dan tokoh masyarakat, warga merasa bahwa telah memperoleh pengetahuan dan ilmu terapan yang sangat bermanfaat dalam pengolahan sampah, warga sangat antusias untuk melanjutkan produksi kerajinan dan mendirikan lembaga Bank Sampah yang dikelola secara serius. Warga berharap kegiatan ini akan dapat ditindak lanjuti dengan adanya pendampingan pemasaran dan pendampingan pengurusan berdirinya Bank Sampah.

\section{SIMPULAN}

Program pemberdayaan masyarakat melalui pengabdian KKN PPM telah dapat memberikan solusi bagi sebagian permasalahan sampah yang dijumpai di D usun Jayan. Solusi yang telah dilaksanakan antara lain yaitu:

1) Peningkatan kesadaran masyarakat dalam memilah sampah dan menjaga kesehatan lingkungan, peningkatan kepedulian masyarakat dalam menangani sampah dan mengurangi volume sampah yang dihasilkan dari rumah tangga masing-masing (reduce).

2) M asyarakat memiliki kemampuan teknis baru dalam melakukan daur ulang sampah, dapat memproduksi hasil kerajinan berbahan baku sampah plastik (reuse dan recycle). 
3) M asyarakat telah memiliki komunitas pengelola sampah yang saat ini didampingi dan dibina oleh D inas Lingkungan Hidup untuk kemudian berproses menjadi Bank Sampah mandiri.

\section{UCAPAN TERIMAKASIH}

1) Lembaga Penelitian, Publikasi dan Pengabdian Masyarakat (LP3M) U niversitas M uhammadiyah Yogyakarta.

2) M asyarakat Dusun Jayan, D esa Kebonagung Kecamatan Imogiri Kabupaten Bantul

3) Dinas Lingkungan Hidup Kabupaten Bantul

4) Jejaring Pen gelola Sampah M andiri (JPSM ) D aerah I stimewa Yogyakarta

\section{CATATAN AKHIR}

1 https://news. detik.com/australiaplus/2832124/ indonesia-nomor-2-terbanyak-membuang-sampahplastik-di-lautan

2 ibid

3 https://www.kompasiana.com/mariahardayanto/ sampah-tanggung-jawab-

siapa_55002aaba333117c6f5101a4

4 Pasal 1 angka 1 Undang Undang Nomor 18 Tahun 2008 tentang Pengelolaan Sampah

5 Bambang Wintoko, Panduan Praktis Mendirikan Bank Sampah.Yogyakarta: Pustaka baru Press, 2015, hlm. 4

6 ibid

7 Paradigma Baru Pengelolaan Sampah, diunduh dari laman http://blh.jogjaprov.go.id/detailpost/ paradigma-baru-pengelolaan-sampah

8 Mundiatun dan Daryanto, Pengelolaan Kesehatan Lingkungan. Yogyakarta: Penerbit Gava Media, 2015, hlm 7

9 Teti Suryati, Bijak dan Cerdas Mengolah Sampah, J akarta: Agromedia, 2009, hlm. 15

10 Sejati, Kuncoro. Pengolahan Sampah Terpadu Dengan Sistem Node, Sub Point, Center Point, Yogyakarta : Kanisius, 2009. HIm 42

11 ibid

12 ibid

\section{DAFTAR PUSTAKA}

Bambang Wintoko, Panduan Praktis Mendirikan Bank Sampah.Yogyakarta: Pustaka baru Press, 2015

Sejati, Kuncoro. Pengolahan Sampah Terpadu Dengan Sistem Node, Sub Point, Center Point, Yogyakarta : Kanisius, 2009.

M. Gelbert, dkk., Konsep Pendidikan Lingkungan Hidup dan "Wall Chart". Buku Panduan Pendidikan Lingkungan Hidup, (Malang: PPPGTNEDC, 1996).

Mundiatun dan Daryanto, Pengelolaan Kesehatan Lingkungan. Yogyakarta: Penerbit Gava Media, 2015

Teti Suryati, Bijak dan Cerdas Mengolah Sampah, J akarta: Agromedia, 2009

Undang Undang Nomor 18 Tahun 2008 tentang Pengelolaan Sampah

https://news. detik.com/australiaplus/2832124/ indonesia-nomor-2-terbanyak-membuangsampah-plastik-di-lautan

https://www.kompasiana.com/mariahardayanto/ sampah-tanggung-jawabsiapa_55002aaba333117c6f5101a4 http://blh.jogjaprov.go.id/detailpost/paradigmabaru-pengelolaan-sampah 